\title{
Precision and Accuracy of the Pre-Surgical Planning of Non-Cemented Total Hip Replacement With Calibrated Digital Images and Acetates
}

\section{Luis Fernando Useche}

Pontificia Universidad Javeriana

Hernando Gaitan-Lee ( $\nabla$ gaitanh@javeriana.edu.co )

Pontificia Universidad Javeriana https://orcid.org/0000-0003-4913-7764

María Alejandra Duarte Tovar

Pontificia Universidad Javeriana

\section{Patrick Dennis Halley}

Pontificia Universidad Javeriana

\section{Alejandro Romero Jaramillo}

Hospital Universitario San Ignacio

\section{Efraim Leal García}

Pontificia Universidad Javeriana

\section{Research Article}

Keywords: Digital templating, analog templating, preoperative planning, total hip arthroplasty, total hip replacement, reliability

Posted Date: May 13th, 2021

DOI: https://doi.org/10.21203/rs.3.rs-468960/v1

License: (c) (1) This work is licensed under a Creative Commons Attribution 4.0 International License. Read Full License 


\section{Abstract}

\section{Background}

Pre-surgical planning in joint replacements allows an estimation of the size and position of the potential implant before surgery. Currently, there are two methods to estimate the size and position: Analogue and digital. This study aims to demonstrate that the hybrid technique is accurate and precise in pre-surgical planning of non-cemented Total Hip Replacement.

\section{Methods}

Concordance-type study against a gold standard, as well as inter and intraobserver consistency evaluation of two orthopedic surgeons and two orthopedic surgery residents. Accuracy was calculated with the intraclass correlation coefficient (ICC), afterwards, the same calculation was done taking into account a margin of error of 1 size above and 1 size below.

\section{Results}

Thirty-eight patients were included in the study. 19 women and 19 men. 22 prostheses $(57.89 \%)$ were right-lateralized and 16 left (42.11\%). 12 prostheses (31.57\%) were Stryker and 26 Johnson \& Johnson (68.43\%) Acetabular cup correlation compared with the gold standard was moderate: ICC reported 0.45 $(95 \% \mathrm{Cl}, 0.15-0.76)$. When adjusted by $+/-1$ size ICC was $0.48(95 \% \mathrm{Cl}, 0.18-0.79)$. On the other hand, results from the femoral stem reported: ICC 0.85 (95\% Cl, 0.07-0.98). When adjusted by $+/-1$ size ICC was $0.86(95 \% \mathrm{Cl}, 0.06-0.99)$.

\section{Conclusions}

Hybrid templating is a reliable substitute for analog or digital templating. It is quick and inexpensive; better results are observed in the femoral component. The level of expertise of the evaluator did not affect the accuracy of the planning.

Level of evidence: Grade IV

\section{Background}

Pre-surgical planning in joint replacements allows an estimation of the size and position of the potential implant before surgery. It has been studied that planning increases the success and survival rate on this procedure [1], decreasing surgical time [1, 2], instability, limb length discrepancy, periprosthetic fractures, and bone loss [3-7]. Another advantage is that it prevents the requirement of implants that are not standard and may not be available at the time of surgery [7].

Historically, pre-surgical planning has been done using printed radiographs $[8,9]$, however, they have fallen into disuse to reduce environmental pollution and improve their availability in various clinical 
settings [10]. Currently, most health institutions use digital systems to handle radiographic information. Technological advances allow planning in a digital format with specialized programs $[11,12]$. This software used in digital planning are not globally available and its high costs restrict access to it. It is essential to find a planning method that does not require the use of printed radiographs or programs for digital measurement that often are not available [13].

In 2015, Petretta et al described a hybrid technique where digital radiographs are used to scale on which planning is performed using templates of the prostheses in acetate. This study showed excellent results in terms of precision and accuracy [13].

The objective of this study is to demonstrate that the hybrid technique is accurate and precise in presurgical planning of non-cemented Total Hip Replacement (THR).

\section{Methods}

This is a retrospective concordance-type study against a gold standard (surgically implanted prosthesis), as well as inter and intraobserver consistency evaluation. The population included patients scheduled for primary Total Hip Replacement in San Ignacio University Hospital between 2018 and 2019, with primary hip osteoarthritis. Exclusion criteria consisted of patients that had a history of fractured pelvis or acetabulum, pelvic or femoral osteotomies, or history of pelvic or femoral tumor. Unsatisfactory radiographs were excluded.

All replacements were made with Accolade 1 femoral stems and Trident acetabular cups (Stryker) or Corail femoral stems and Pinnacle acetabular cups (Johnson \& Johnson).

Preoperative radiographs were taken with magnification control to allow the surgeon to plan the surgery accurately. For this purpose, the tube of the X-ray equipment was placed one meter away from the patient using a $28 \mathrm{~mm}$ diameter metal sphere for magnification control and the pubic-centered beam $[14,15]$. The metallic magnification control should be placed at the level of the femur on the outer or inner side of the thigh for the anteroposterior radiograph, and on the anterior or posterior face of the thigh for the lateral radiography [16-18] (Fig. 1).

All X-rays were planned by two fourth-year orthopedic surgery residents and two orthopedic surgeons' specialists in joint replacements. The planning criteria were those established by De la Valle and Cols [19]. On the day of surgery, intraoperative prosthetic components were recorded. Surgeons were blinded and did not know preoperative planning.

The information was collected in a Microsoft Excel spreadsheet based on the review of the records of each patient's personal medical history that met the inclusion criteria, data collection was safely archived by the research team, both in electronic and physical format.

Sample size calculation was done using the R version 3.5.1 program, with an expected agreement of $90 \%$, accuracy of $5 \%$ (error), and 95\% confidence level; obtaining 38 patients and a total of 304 measurements 
[20].

Accuracy measurement was first calculated with the proportion of cases in which the method corresponds exactly to the components, afterward the same calculation was done taking into account a margin of error of 1 size above, and 1 size below. Using the same technique as Petretta et al [13], histograms depicting size difference between the templated and implanted component and their normal distribution curve were generated in STATA (Fig. 2).

Intra-observer and inter-observer reliability were calculated using the intraclass correlation coefficient (ICC). ICC is a method that allows evaluating the general agreement between two or more measurement or observation methods based on an analysis of variance model (ANOVA) with repeated measures. Values below 0.4 indicate low reliability, between 0.4 and 0.75 between fair and good reliability, and values above 0.75 refer to excellent reliability [21]. All statistical analyses were done with STATA program version 13.0 .

The work was presented and approved by the ethics committee of the San Ignacio University Hospital and the Pontificia Universidad Javeriana. Given that no intervention was performed on the patients and the evaluated x-ray images did not allow their identification nor would be published in the document, the ethics committee considered that informed consent was not required. All methods were carried out in accordance with relevant international and Colombian guidelines and regulations

\section{Results}

Thirty-eight patients were included in the study. 19 women and 19 men. 22 prostheses $(57.89 \%)$ were right-lateralized and 16 were left $(42.11 \%) .12$ prostheses $(31.57 \%)$ were Stryker and 26 Johnson \& Johnson (68.43\%).

Acetabular cup correlation compared with the gold standard was moderate: ICC reported $0.45(95 \% \mathrm{Cl}$, $0.15-0.76)$. When adjusted by $+/-1$ size ICC was $0.48(95 \% \mathrm{Cl}, 0.18-0.79)$. On the other hand, results from the femoral stem reported: ICC 0.85 (95\% Cl, 0.07-0.98). When adjusted by $+/-1$ size ICC was 0.86 $(95 \% \mathrm{Cl}, 0.06-0.99)$. The results are summarized in Table 1.

An independent analysis of both the acetabular cup and the femoral stem was carried out for each observer, which is summarized in Table 2.

Evaluator 1 and 3 where Orthopedic surgeon specialists in joint replacements. Evaluator 1 acetabular cup ICC was 0.62 (95\% Cl, 0.17-0.95). When adjusted by $+/-1$ size ICC was $0.70(95 \% \mathrm{Cl}, 0.15-0.99)$.

Evaluator 3 acetabular cup ICC was 0.27 (95\% Cl, 0.2-0.65). When adjusted by $+/-1$ size ICC was 0.31 $(95 \% \mathrm{Cl}, 0.22-0.70)$. Evaluator 1 femoral stem ICC was 0.86 ( $95 \% \mathrm{Cl}, 0.07-1.00)$. When adjusted by $+/-1$ size ICC was 0.86 (95\% Cl, 0.073-1.00). Evaluator 3 femoral stem ICC was 0.91 (95\% Cl, 0.05-1.00). When adjusted by $+/-1$ size ICC was $0.92(95 \% \mathrm{Cl}, 0.046-1.00)$. 
Evaluator 2 and 4 where fourth year orthopedic surgery residents. Evaluator 2 acetabular cup ICC was 0.65 (95\% Cl, 0.16-0.96). When adjusted by $+/-1$ size ICC was 0.69 (95\% Cl, 0.15-0.98). Evaluator 4 acetabular cup ICC was $0.63(95 \% \mathrm{Cl}, 0.16-0.97)$. When adjusted by +/-1 size ICC was $0.67(95 \% \mathrm{Cl}$, 0.17-0.96). Evaluator 2 femoral stem ICC was 0.82 (95\% Cl, $0.09-0.99)$. When adjusted by $+/-1$ size ICC was 0.82 (95\% Cl, 0.08-0.99). Evaluator 4 femoral stem ICC was 0.85 (95\% Cl, 0.07-1.00). When adjusted by $+/-1$ size ICC was $0.85(95 \% \mathrm{Cl}, 0.08-1.00)$.

\section{Discussion}

The traditional method for the pre-surgical planning of hip replacements is a physical x-ray with a magnification between $10 \%$ and $20 \%[8,9]$. Two types of templates are used for planning: the acetabular cup and the femoral component. The profiles drawn on the transparent templates overlap the hip radiographs where the anatomical segments are found until the size that fits is found [17]. The accuracy has been reported of $52 \%$ in the acetabular component and $56 \%$ in the femoral component [22].

The emergence of new digital technologies has decreased the use of physical radiographs, altering the traditional way of pre-surgical planning for joint replacements [12, 22]. In the market, there are multiple software that allows digital planning however, their costs are high, especially in the context of a developing country. Available literature has reported an accuracy of $38 \%$ of the acetabular component and $35 \%$ of the femoral component using this method [23].

Hybrid planning was initially described in 2006 for total hip replacements, consisting of measuring digital images on a liquid crystal monitor to scale so that the image magnifier is the same size as the metric system of the templates used for planning. After this, traditional planning is carried out with acetates [24].

In 2015 Petretta et al. found an accuracy of $77 \%$ and 0.75 in the planning of the acetabular and femoral component respectively. In their study, 260 measurements were made by 5 different people with different levels of experience on radiographs of 52 patients. They found no inter or intra-observer differences and when compared against digital planning. Additionally, it was superior in the planning of the femoral component compared with the digital method, without differences in the acetabular cup [13]. Also Wang et al, in 2017 report ICC for acetabular templating of 0.918 and ICC for femoral component templating of 0.944 [25].

Taking into account the context of a university hospital in a developing country, we seek to save costs and at the same time achieve a reliable and highly effective method to obtain the best clinical results in our patients. The above motivates us to study the precision and accuracy of this method.

Our study shows that preparatory planning with the hybrid method has adequate accuracy when compared to the prosthesis that was finally implanted. The femoral component presented in all measurements a correlation near 0.9 (even without adjustment of sizes) which is interpreted as excellent [26]. Similarly, no differences were found concerning the level of experience or training of the person who 
made the measurements. This accuracy was so high that we may infer that in the clinical setting planning the femoral component could not require to take a size above or below.

On the other hand, the accuracy of the acetabular component was moderate in all measurements (around 0.45) [26]. However, in this case, having one size above or one below did not significantly affect the accuracy. A hypothesis that may explain the low reliability is that acetabulum is a tridimensional structure with ellipse shape, which hinders the measures more than a circumference structure, such as the femur diaphysis. Furthermore, if we take into account that plain radiography represents only two dimensions. Results suggest that in clinical practice the minimum need for one or two sizes above or below the planning should be anticipated before entering surgery.

It is important to mention that when an independent analysis between the observers was made, significant differences were noticed (Table 2). This was especially important in the acetabular cup measurement of evaluator 3 which had very low ICC, even with the size correction the discrepancy in relation to the others was significant. When we performed a retrospective analysis, we found that this evaluator had had an error in the calibration of the measurements in a systematic way that could explain his inferior results.

\section{Conclusions}

The hybrid method is an effective method for planning the total non-cemented primary hip replacements. This technique shows high concordance with the implanted prosthesis and a high correlation between the different evaluators regardless of their level of expertise and training, especially in the femoral stem. Additionally, it is an alternative that does not increase treatment costs. Given the above, it is an effective, safe, and economical method that can be used in all areas but notably at hospitals in developing countries.

\section{Abbreviations}

- Intraclass correlation coefficient: ICC

- Total Hip Replacement: THR

- Analysis of variance model: ANOVA

\section{Declarations}

- Ethics approval and consent to participate: The study was submitted and approved by the ethics committee of the San Ignacio University Hospital and the Pontificia Universidad Javeriana. As it is a retrospective study, it does not require the informed consent of the participants upon admission.

- Consent for publication: Not applicable

- Availability of data and materials: The datasets used and/or analysed during the current study are available from the corresponding author on reasonable request. 
- Competing interests: The authors declare that they have no competing interests.

- Funding: The work was financed with the authors' own resource

- Authors' contributions: LFU devised the work, participated in the data collection and the writing of the article. HGL participated in the data collection, statistical analysis, and writing of the article. MAD participate in data collection and statistical analysis. PDH devised the work, participated in the data collection. ARJ assisted in the data collection. ELG devised the work, participated in the data collection.

- Acknowledgments: Nazly Tatiana Carrillo and Paola Alejandra Valderrama, fourth-year residents for their participation in the measurements.

\section{References}

1. Blackley HR, Howell GE, Rorabeck CH. Planning and management of the difficult primary hip replacement: preoperative planning and technical considerations. Instr Course Lect. 2000;49:3-11.

2. Schiffers N, Schkommodau E, Portheine F, Radermacher K, Staudte HW. [Planning and performance of orthopedic surgery with the help of individual templates] (in German). Orthopä de. 2000;29:636640.

3. Eggli S, Pisan M, Muller ME. The value of preoperative planning for total hip arthroplasty. J Bone Joint Surg Br. 1998;80:382-390.

4. Goldstein WM, Gordon A, Branson JJ. Leg length inequality in total hip arthroplasty. Orthopedics. 2005;28(9 suppl):s1037-s1040. 区

5. Haddad FS, Masri BA, Garbuz DS, Duncan CP. The prevention 囚of periprosthetic fractures in total hip and knee arthroplasty. खOrthop Clin North Am. 1999;30:191-207.

6. Schiffers N, Schkommodau E, Portheine F, Radermacher K, Staudte HW. Planning and performance of orthopedic surgery with the help of individual templates. Orthopa" de. 2000;29:636-640.

7. Hendrikus J.A, Laumen M, Van Pul C, Van Mourik J. A New Digital Preoperative Planning Method for Total Hip Arthroplasties. Clin Orthop Relat Res (2009) 467:909-916

8. Carter LW, Stovall DO, Young TR. Determination of accuracy of preoperative templating of noncemented femoral prosthesis. J Arthroplasty. 1995;10:507-513.

9. Knight JL, Atwater RD. Preoperative planning for total hip arthroplasty: quantitating its utility and precision. J Arthroplasty. 1992;7:403-409. \

10. The B, Diercks R, van Ooijen P, Van Horn JR. Comparison of analog and digital preoperative planning in total hip and knee arthroplasty. Acta Orthop. 2005;76:78-84.

11. Crooijmans HJ, Laumen AM, van Pul C, van Mourik JB. A new digital preoperative planning method for total hip arthroplasties. Clin Orthop Relat Res 2009;467:909-16.

12. Viceconti M, Chiarini A, Testi D, Taddei F, Bordini B, Traina F, Toni A. New aspects and approaches in pre-operative planning of hip reconstruction: a computer simulation. Langenbecks Arch Surg. 2004;389:400-404. 
13. Petretta R,Strelzow J, Ohly N, Misur P, Masri B. Acetate Templating on Digital Images Is More Accurate Than Computer-based Templating for Total Hip Arthroplasty. Clin Orthop Relat Res symposium: 2014 international hip society proceedings

14. Sears, Z., Young, Freedman. , Física Universitaria. 11a edición ed. Vol. Volumen 2. 2004: Pearson. 『

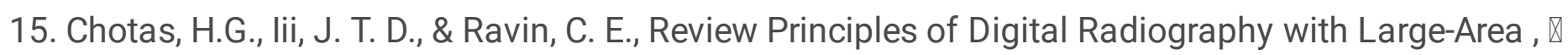
Electronically Readable Detectors : A Review of the Basics Radiology, 1999. 210: p. 595-599.

16. Franken M, G.B., Heyligers I., A comparison of four systems for calibration when templating for total

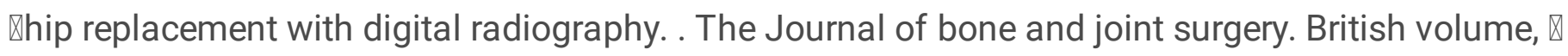
2010 Jan (92(1)): p. 136-41.

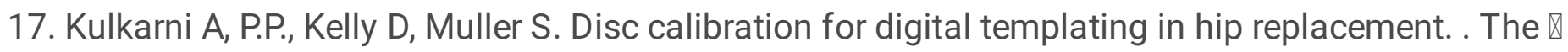
Journal of bone and joint surgery. British volume. , 2008 Dec 90(12): p.:1623-6. \

18. Wimsey S, P.R., Shaw G., Accurate scaling of digital radiographs of the pelvis. A prospective trial of $\mathbb{Z}$ two methods. J Bone Joint Surg Br, 2006. 88. \

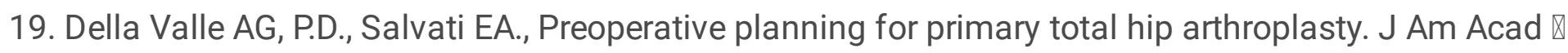
Orthop Surg, 2005. Nov;13(7): p. 455-62. 『

20. Rotondi MA, Donner A. A confidence interval approach to sample size estimation for interobserver agreement studies with multiple raters and outcomes. J Clin Epidemiol. 2012 Jul;65(7):778-84. doi: 10.1016/j.jclinepi.2011.10.019. Epub 2012

21. Cortés-Reyes É, Rubio-Romero J, Gaitán-Duarte H. Métodos estadísticos de evaluación de la concordancia y la reproducibilidad de pruebas diagnósticas. Rev Colomb Obstet Ginecol [Internet]. 2010 Sep [cited 2020 July 03] ; 61 ( 3 ): 247-255. Available from: http://www.scielo.org.co/scielo.php? script=sci_arttext\&pid=S0034-74342010000300009\&lng=en.

22. Davila JA, Kransdorf MJ, Duffy GP. Surgical planning of total hip \arthroplasty: accuracy of computer-assisted EndoMap software 『in predicting component size. Skeletal Radiol. 2006;35:390393.凶

23. Gamble P, de Beer J, Petruccelli D, Winemaker M. The accuracy of digital templating in uncemented total hip arthroplasty. J Arthroplasty. 2010 Jun;25(4):529-32.

24. Oddy MJ, Jones MJ, Pendegrass CJ, Pilling JR, Wimhurst JA. Assessment of reproducibility and accuracy in templating hybrid total hip arthroplasty using digital radiographs. J Bone Joint Surg Br. 2006;88:581-585.

25. Wang Q, Xiao J, Zhu L, et al. Acetate templating on calibrated standing digital radiograph improves accuracy of preoperative templating for total hip arthroplasty. Orthop Traumatol Surg Res. 2017;103(3):341-347. doi:10.1016/j.otsr.2016.12.022

26. The B, Diercks RL, van Ooijen PM, van Horn JR. Comparison of analog and digital preoperative planning in total hip and knee arthroplasties. A prospective study of 173 hips and 65 total knees. Acta Orthop. 2005 Feb;76(1):78-84.

\section{Tables}


Due to technical limitations, table 1 and 2 is only available as a download in the Supplemental Files section.

\section{Figures}
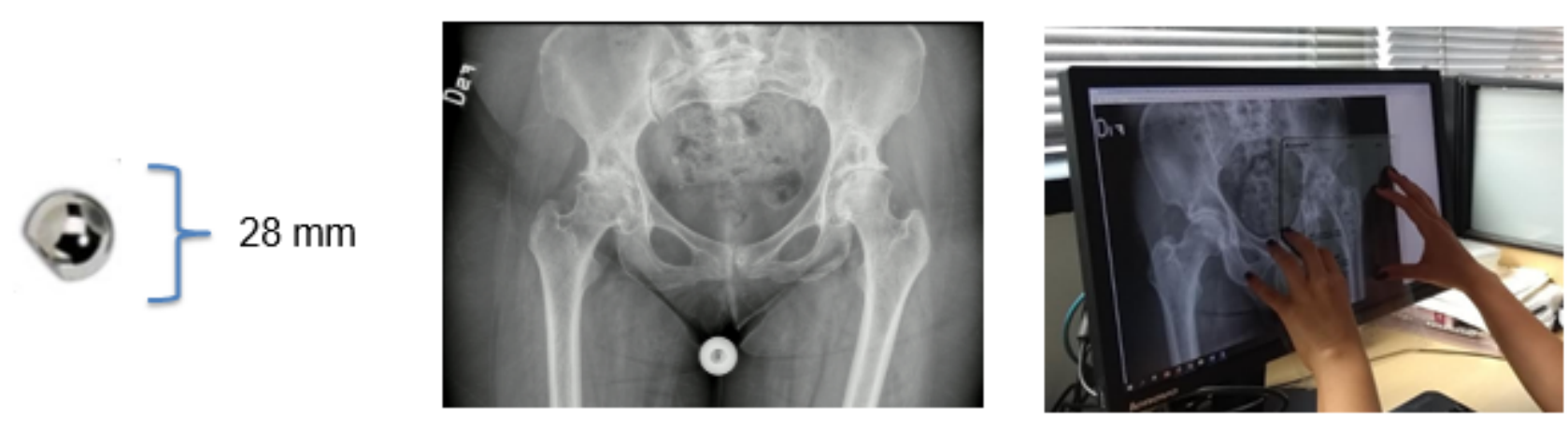

\section{Figure 1}

The metallic magnification control should be placed at the level of the femur on the outer or inner side of the thigh for the anteroposterior radiograph, and on the anterior or posterior face of the thigh for the lateral radiography
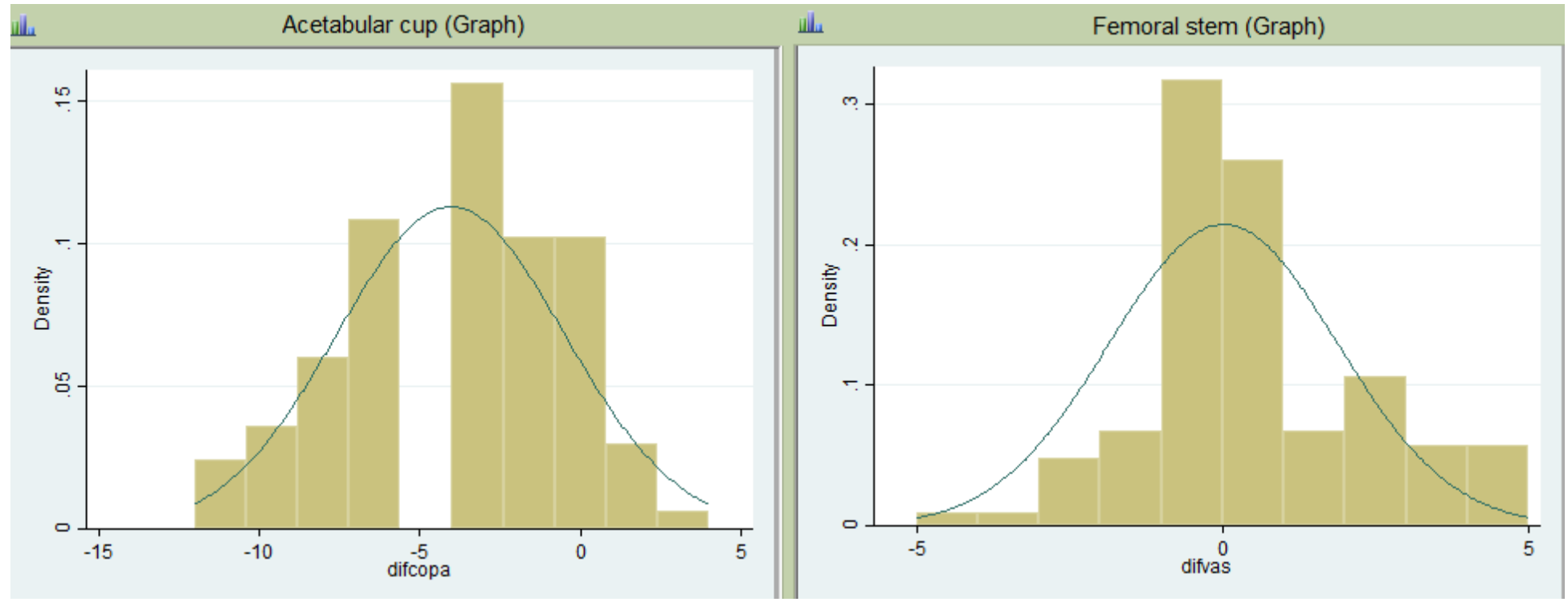

\section{Figure 2}

Using the same technique as Petretta et al [13], histograms depicting size difference between the templated and implanted component and their normal distribution curve were generated in STATA

\section{Supplementary Files}

This is a list of supplementary files associated with this preprint. Click to download. 
- Table1.png

- Table2.png

Page 10/10 